\title{
ANÁLISE DE TRILHA I: ANÁLISE DO RENDIMENTO DE GRÃOS E SEUS COMPONENTES
}

\author{
PATH ANALYSIS. I: ANALYSIS OF THE YIELD OF GRAINS AND ITS COMPONENTS
}

\section{Jefferson Luís Meirelles Coimbra ${ }^{1}$ Altamir Frederico Guidolin ${ }^{2}$ Fernando Irajá Felix de Carvalho $^{3}$ Silvana Manfredi Meirelles Coimbra ${ }^{4}$ Volmir Sergio Marchioro ${ }^{5}$}

RESUMO

Trinta e dois acessos de feijão (Phaseolus vulgaris L.) foram avaliados em Lages/SC, através da influência de oito caracteres de importância agronômica sobre a produção de grãos por unidade de área. O experimento, em blocos casualizados com quatro repetições, foi conduzido no período de "safrinha" no ano agrícola de 1996/97. Este trabalho teve como objetivo estimar os coeficientes de trilha entre os caracteres primários $e$ secundários. O primeiro grupo de variáveis (primários) foi constituído pelo número de grãos por legume, número de legumes por planta, peso de mil grãos e a população de plantas (POP), e o segundo grupo (secundários), pelo número de dias entre a emergência e o florescimento $(F L)$, número de dias entre a emergência e a maturação de colheita (MC), estatura de planta $(E P) e$ o ponto de inserção do primeiro legume (PIL). Pela análise do coeficiente de trilha, ficaram caracterizados e avaliados os efeitos diretos e indiretos dos caracteres primários NLP e PMG, revelando os maiores efeitos diretos associados à alta correlação. O NLP foi altamente influenciado por plantas de maturação precoce e estatura de planta elevada. Assim, os coeficientes de trilha permitem concluir que os maiores efeitos diretos sobre o rendimento de grãos estão associados, principalmente a NLP, PMG, NGL e ciclo da planta.

Palavras-chave: Phaseolus vulgaris L., critérios de seleção, correlações.

\section{SUMMARY}

Thirty two bean accesses (Phaseolus vulgaris L.) were evaluated for the influence of eight characters of agronomic importance the production of grains for unit of area, in Lages/SC. The experiment, in randomized blocks with four repetitions, was conducted during the period off-season in the agricultural year of
1996/97. This work aimed estimating the degree of association between grain yield and its secondary components. The first group of variables (primary) was constituted by the number of grains per pod, number of pods per plant, weight of a thousand grains and the population of plants (POP). The second group (secondary), was constituted by the number of days between emergence and flowering (FL), number of days between emergence and harvesting point $(M C)$, plant stature $(E P)$ and the height of first pod insertion (PIL). For the analysis of the trail coefficient, the direct and indirect effects of primary characters NLP and PMG were characterized and evaluated, revealing the large direct effects associated with the high correlation. The NLP was highly influenced by plants of shorter cycle and higher stature. The trail coefficients allow to point out that the largest direct effects on the yield of grains NLP are mainly associated to $P M G, N G L$ and cycle of the plant.

Key words: Phaseolus vulgaris L., selection criteria, correlations.

\section{INTRODUÇÃO}

O Brasil é um dos principais produtores mundiais de feijões, juntamente com a Índia, China, México e os Estados Unidos, sendo o primeiro produtor e consumidor mundial do gênero Phaseolus. A comercialização do feijão proporciona uma das principais receitas das culturas de verão, o que significa uma injeção de recursos em um momento financeiramente crítico, principalmente para os pequenos agricultores (BISOGNIN et al., 1997).

\footnotetext{
${ }^{1}$ Engenheiro Agrônomo, Aluno do Curso de Pós-graduação, Universidade Federal de Pelotas (UFPel), Pelotas, RS. Bolsista da CAPES, CP 354, 96001-970, Capão do Leão, RS. E-mail: jlmcpos@ufpel.tche.br. Autor para correspondência.

${ }^{2}$ Engenheiro Agrônomo, MSc., Professor de Genética da Universidade do Estado de Santa Catarina.

${ }^{3}$ Engenheiro Agrônomo, PhD., Professor da UFPel. Pesquisador do CNPq.

${ }^{4}$ Engenheiro Agrônomo, Estagiário do Departamento de Fitossanidade da UFPel.

${ }^{5}$ Acadêmico do Curso de Agronomia.
} 
O potencial de rendimento (RAMALHO et al., 1993) é um caráter complexo, resultante dos efeitos multiplicativos dos seus componentes primários. Já para FEHR (1987), o potencial de rendimento final de grãos é dependente de processos fisiológicos que podem ter influência direta e/ou indireta sobre este caráter primário e básico.

$\mathrm{O}$ incremento da produção brasileira de grãos de feijão tem sido pequeno. Para NADAL (1992), a produtividade média do Brasil está em torno de $470 \mathrm{~kg} / \mathrm{ha}$. Para melhorar esta condição de baixa produtividade de grãos por unidade de área do feijão, é necessário um substancial impacto nos programas de melhoramento genético do feijão.

Para MIRANDA et al. (1988), estimativas de correlações parcial e canônica, e análise de trilha entre os componentes da produção são de grande importância para os melhoristas determinarem o procedimento mais eficiente na condução de um programa de melhoramento genético da cultura do feijão. Segundo CRUZ e REGAZZI (1997), os coeficientes de correlação simples, apesar de serem de utilidade na quantificação da magnitude e direção da influência de fatores na determinação de caracteres complexos, não dão a exata importância relativa aos efeitos diretos e indiretos desses fatores.

Neste sentido, identificar os caracteres que evidenciem os maiores efeitos diretos e indiretos sobre o rendimento de grãos é uma das prioridades da pesquisa da cultura do feijão, justificando-se o objetivo deste trabalho, que foi de procurar identificar e caracterizar os componentes primários e secundários mais importantes na seleção indireta para aumentar o rendimento de grão do feijão.

\section{MATERIAL E MÉTODOS}

Trinta e dois acessos de feijão preto foram caracterizados no ano agrícola de 1996/97, no município de Lages/SC, situado no Planalto Catarinense. Foram avaliados 13 caracteres, dos quais nove quantitativos, utilizados para a determinação das correlações fenotípicas e, posteriormente, para a análise dos coeficientes de trilha. $\mathrm{O}$ diagrama adotado (figura 1) incluiu as seguintes variáveis: 1) variável principal - produtividade de grãos por unidade de área em $\mathrm{kg} / \mathrm{ha}$ (PROG); 2) variáveis explicativas primárias - número de grãos por legume (NGL), número de legumes por planta (NLP), peso de mil grãos (PMG) e número de plantas por unidade de área (POP); e quatro variáveis explicativas secundárias - número de dias para floração (FL) e colheita (MC), estatura de planta (EP) e ponto de inserção do primeiro legume (PIL). As avaliações realizadas foram baseadas nos estádios de crescimento da cul-

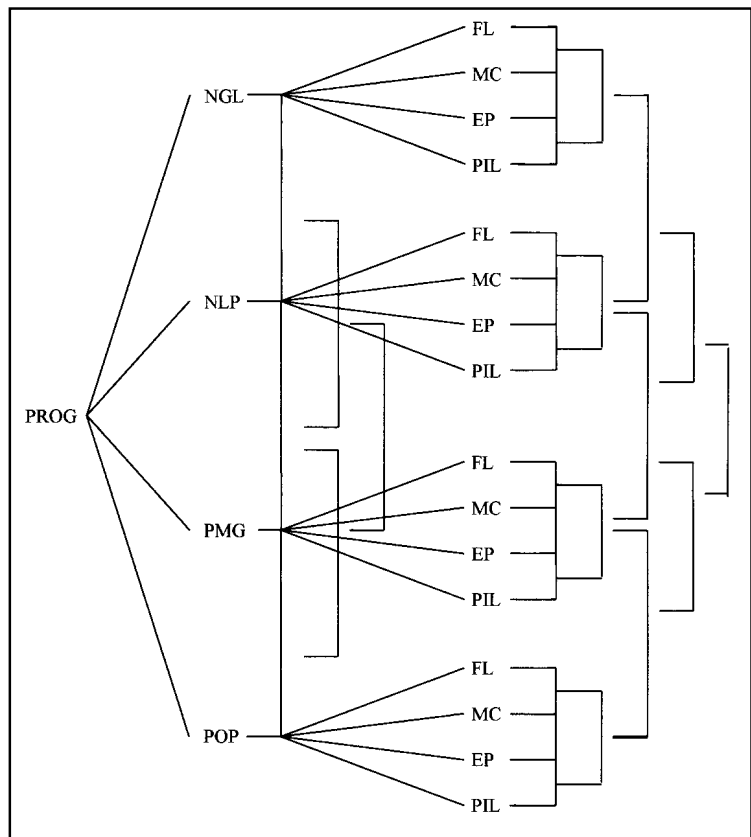

Figura 1 - Diagrama causal em cadeia, demonstrando o relacionamento dos componentes secundários $(\mathrm{FL}=$ número de dias para a floração; $\mathrm{MC}=$ número de dias para a maturação de colheita; $\mathrm{EP}=$ estatura de planta em $\mathrm{cm} ; \mathrm{PIL}=$ ponto de inserção do primeiro legume) sobre os componentes primários $(\mathrm{NGL}=$ número de grãos por legume; $\mathrm{NLP}=$ número de legumes por planta; $\mathrm{PMG}=$ peso de mil grãos; $\mathrm{POP}=$ número de plantas por unidade de área) e desses sobre a variável rendimento de grãos (PROD).

tura, seguindo a escala proposta pelo CIAT (1991). A emergência foi avaliada no estádio $V_{1}$, a data de floração no estádio $\mathrm{R}_{6}$ e a data de maturação de colheita no estádio $\mathrm{R}_{9}$, quando $50 \%$ das plantas da parcela alcançaram sua maturação fisiológica. A determinação do ponto de inserção do primeiro legume foi avaliada no estádio $\mathrm{R}_{7}$, quando surgiu o primeiro legume com mais de $2,5 \mathrm{~cm}$ de comprimento. No estádio $R_{9}$, foi atribuído nota geral aos demais caracteres avaliados, que correspondeu a nota de adaptação reprodutiva em função das observações gerais de desenvolvimento, carga de legumes, tamanho do legume, número de legumes por planta, porte, acamamento, etc.

O preparo do solo foi realizado de forma convencional, segundo recomendações técnicas relatadas por WILDNER (1992). As adubações de base constaram de 15,55 e $60 \mathrm{~kg} / \mathrm{ha}$ de NPK. A adubação de cobertura, realizada no estádio de duas folhas trifolioladas, foi de $70 \mathrm{~kg} / \mathrm{ha}$ de $\mathrm{N}$ (uréia), sendo ambas realizadas de acordo com as recomendações descritas por BALDISSERA \& SCHERER (1992). O controle de plantas invasoras foi efetuado 
com aplicação de $2 \mathrm{~kg} / \mathrm{ha}$ de Metachlor, sendo posteriormente realizada capina manual para eliminação de invasoras remanescentes. $\mathrm{O}$ controle de pragas foi através da aplicação de inseticida Methamidophos (Tamaron BR), nas doses de 0,5 a 1,01/ha do produto comercial, realizando-se sempre que necessário.

O delineamento experimental utilizado foi blocos ao acaso, com quatro repetições para cada tratamento. A unidade experimental era composta por duas fileiras de $5 \mathrm{~m}$ de comprimento com 10 plantas/m linear ou 200.000 plantas/ha, a espaços de $0,5 \mathrm{~m}$ entre fileiras e $0,2 \mathrm{~m}$ entre covas dentro das fileiras. A área útil formada de duas fileiras compreendia $4 \mathrm{~m}^{2}$. A semeadura foi realizada no dia 09 de fevereiro de 1996. De acordo com o zoneamento agroclimático de $\mathrm{SC}$, não coincidiu com o período preferencial para a cultura naquela região, onde o cultivo da safra compreende normalmente os meses de setembro a novembro e, o de safrinha, os meses de janeiro a fevereiro. Não se recomenda o cultivo de safrinha no Planalto Catarinense, devido à possibilidade de ocorrência de baixas temperaturas (geadas) no final do ciclo reprodutivo; fato este, que poderia limitar o potencial de rendimento de grãos. Entretanto, esta condição não foi verificada no ano agrícola 1996/97, o que permitiu que os dados fossem suficientemente representativos da região.

Para satisfazer a condição de aditividade do modelo matemático, os dados foram logaritmizados. A resolução na forma matricial foi dada pelo sistema de equações normais (CRUZ e REGAZZI, 1997).

$X^{\prime} \cdot X \cdot \beta=X^{\prime} \cdot \alpha, \quad$ em que:

$X^{\prime} \cdot X=$ matriz não singular das correlações entre as variáveis primárias;

$\beta=$ vetor coluna de coeficiente de trilha; e

$\mathrm{X}^{\prime} . \alpha=$ vetor coluna das correlações entre as variáveis principal e primárias.

A solução de mínimos quadrados deste sistema é dada por: $\beta=\left(X^{\prime} \cdot X\right)^{-1}$ $\mathrm{X}^{\prime} . \alpha$. As análises foram realizadas com auxílio do programa computacional GENES (CRUZ, 1997).

\section{RESULTADOS E DISCUSSÃO}

As estimativas de correlação fenotípica $\left(\mathrm{r}_{\mathrm{P}}\right)$ avaliadas para os nove caracteres agronômicos estão incluídas na tabela 1 . A magnitude das $r_{P}$ entre todos os caracteres agronômicos avaliados variou de $-0,003$ a 0,89 .

De acordo com os autores SANTOS e VENCOVSKY (1986), as correlações são, em geral, explicadas pelo efeito aditivo dos genes, afetando dois caracteres simultaneamente. Portanto, o conhecimento do grau de associação entre caracteres agronômicos é de grande importância para os melhoristas, principalmente porque a seleção sobre determinado caráter pode alterar o comportamento do outro.

A correlação fenotípica mede o grau de associação de dois caracteres provenientes dos efeitos de ambiente e genético, sendo este último efeito o principal responsável pela fração herdável dos genitores para as progênies. Ainda na tabela 1, pode ser observado uma boa concordância na direção e na magnitude da $r_{P}$ para a maioria dos pares de caracteres agronômicos avaliados. Por outro lado, alguns pares de caracteres (FL/PMG e FL/PROG), evidenciaram um coeficiente de correlação negativo. Esta discordância, em magnitude e direção dos parâmetros estimados, evidencia que as causas de variação genética e de ambiente influenciaram os caracteres por meios de diferentes mecanismos fisiológicos (FALCONER, 1987).

Também pode ser observado na tabela 1 que a $r_{P}$ revelou valores negativos para todos os pares de caracteres explicativos secundários (FL, MC, EP e PIL) quando correlacionados com a variável rendimento de grãos. As estimativas do coefi-

\begin{tabular}{|c|c|c|c|c|c|c|c|c|c|}
\hline Caracteres & FL & $\mathrm{MC}$ & EP & PIL & NGL & NLP & PMG & POP & PROG \\
\hline FL & 1,00 & 0,41 & 0,19 & 0,29 & $-0,21$ & 0,11 & $-0,22$ & $-0,07$ & $-0,13$ \\
\hline $\mathrm{MC}$ & & 1,00 & 0,27 & 0,01 & $-0,26$ & 0,24 & $-0,02$ & $-0,33$ & $-0,25$ \\
\hline EP & & & 1,00 & 0,17 & $-0,36$ & 0,23 & 0.13 & $-0,19$ & $-0,06$ \\
\hline PIL & & & & 1,00 & $-0,30$ & $-0,32$ & $-0,003$ & 0,26 & $-0,18$ \\
\hline NGL & & & & & 1,00 & 0,09 & $-0,10$ & $-0,13$ & 0,37 \\
\hline NLP & & & & & & 1,00 & $-0,29$ & $-0,77$ & 0,89 \\
\hline PMG & & & & & & & 1,00 & 0,18 & 0,46 \\
\hline POP & & & & & & & & 1,00 & 0,35 \\
\hline PROG & & & & & & & & & 1,00 \\
\hline
\end{tabular}

${ }^{1 /} \mathrm{FL}=$ número de dias para a floração; $\mathrm{MC}=$ número de dias para a maturação de colheita; $\mathrm{P}=$ estatura de planta em $\mathrm{cm} ; \mathrm{PIL}=$ ponto de inserção do primeiro legume; $\mathrm{NGL}=$ número de grãos por legume; $\mathrm{NLP}=$ número de legumes por planta; $\mathrm{PMG}=$ peso de mil grãos; $\mathrm{POP}=$ número de plantas por unidade de área; PROG= rendimento de grãos por unidade de área. 
ciente de correlação fenotípicas entre os caracteres FL, MC, ET e PIL associados com o caráter PROG e PMG, de forma geral, foram de pequena magnitude e, na grande maioria, de direção contrária. Este fato também foi observado por COLLICCHIO et al., (1997) que afirmam não existir associação entre os caracteres EP, PROG e PMG. Considerando a correlação fenotípica da tabela 1 , pode ser detectado que o maior potencial de rendimento de grãos e o maior peso de grãos estão associados com o menor ciclo vegetativo e reprodutivo, com a menor estatura de planta e de inserção do primeiro legume, concordando com resultados relatados por SANTOS \& VENCOVSKY (1986).

Inicialmente, foi realizada uma análise considerando todos os oito caracteres como variáveis primárias sobre a produtividade de grãos por unidade de área. Esta análise apontou os maiores efeitos diretos para os caracteres número de grãos por legume (NGL), número de legumes por planta (NLP), peso de mil grãos (PMG) e população de plantas (POP), sendo assim classificados como primários e os caracteres emergência ao florescimento (FL), emergência a maturação de colheita (MC), estatura de planta (EP) e estatura de inserção do primeiro legume ( PIL), como variáveis secundárias. Tal fato não significa que toda a variação dos componentes primários seja explicada por estas variáveis secundárias.

$\mathrm{Na}$ tabela 2, estão inseridas as estimativas dos efeitos diretos e indiretos dos componentes primários da produção (NGL, NLP, PMG e POP) sobre a variável principal (PROG). Os caracteres NLP e PMG, seguido pelo NGL, evidenciaram os maiores efeitos diretos pronunciados, alta correlação com PROG e efeitos indiretos relativamente baixos, devido, provavelmente, ao efeito indireto via NLP.

Os efeitos indiretos foram relativamente baixos, exceto para o caráter POP com efeito indireto via NLP, que apontou uma estimativa de $62 \%$, aproximadamente. Este resultado é um indicativo da viabilidade da seleção indireta para obtenção de ganhos no caráter de maior importância primária. $\mathrm{O}$ caráter NGL apontou um coeficiente de correlação baixa com PROG e revelou um efeito direto alto, comparativamente com outros caracteres e, principalmente, quando comparado com a variável residual.

A baixa correlação deste caráter está associada ao efeito indireto negativo, via NLP e, principalmente, via PMG. O caráter POP apontou uma baixa correlação, porém positiva, e também baixo efeito direto e negativo, indicando que a seleção truncada neste caráter pode não proporcionar ganhos satisfatórios na variável PROG. Ainda na tabela 2, pode ser constatado que o caráter NGL, com alta correlação positiva, mas com baixo efeito direto, indica que a seleção truncada no caráter auxiliar pode não proporcionar ganhos satisfatórios na variável básica (PROG). Nestes casos, a melhor estratégia é a seleção simultânea de caracteres, com ênfase também nos caracteres cujos efeitos indiretos são significativos (SANTOS et al., 1994; CRUZ \& REGAZZI, 1997).

O coeficiente de determinação $\left(\mathrm{r}^{2}\right)$ total, associado ao efeito residual nulo, indicam que os 
efeitos dessas variáveis primárias explicam a totalidade dos efeitos apresentados no diagrama causal adotado para PROG. O caráter POP, de alta correlação positiva com a variável básica (PROG), mas com efeito direto em sentido contrário, indica a ausência de causa e efeito, ou seja, o caráter POP não é a principal variável que determina a alteração da variável básica. Este fato indica que a seleção direta sobre NLP, PMG e NGL será eficiente para aumentar a produção de grãos por unidade de área.

Os resultados da análise de trilha dos caracteres secundários, para cada componente primário, estão descritos na tabela 3. Através deles é possível identificar caracteres que podem maximizar as respostas correlacionadas num programa de melhoramento genético da cultura. Todos os componentes secundários apresentaram correlações negativas com o componente primário NGL, ou seja, para o caráter NGL o efeito indireto não apontou correlação positi- va, indicando que a seleção indireta sobre o caráter primário, número de grãos por legume não é viável. Por outro lado, o caráter NLP apontou um coeficiente de correlação negativo apenas para o caráter PIL. Esta mesma situação ocorreu para o caráter PMG, porém quando correlacionado com o FL. Assim sendo, para aumentar o NLP devem ser considerados os ciclos vegetativos e reprodutivos mais precoces, que podem estar relacionados à baixa pluviosidade após o plantio dos genótipos e ao pouco desenvolvimento do sistema radicular que a semeadura tardia (dezembro a fevereiro) favorece.

De modo geral, pode ser constatado, pela tabela 3, que os efeitos diretos não tiveram o mesmo sinal das correlações para o caráter primário NGL e sua magnitude não é relevante para o programa de melhoramento genético da cultura, pois, na maioria das vezes, não supera a estimativa do efeito residual. Sendo assim, a variável secundária não é a principal

Tabela 3 - Estimativas de efeitos diretos e indiretos dos componentes secundários sobre os componentes primários na produção de grãos de feijão preto. Lages/SC, 1996.

\begin{tabular}{|c|c|c|c|c|}
\hline Descrição do Efeito & \multicolumn{4}{|c|}{ Componente Primário } \\
\hline Efeito direto de FL & $-0,026871$ & 0,119419 & $-0,277934$ & 0,002267 \\
\hline via EP & $-0,050660$ & 0,040865 & 0,030173 & $-0,028644$ \\
\hline via PIL & $-0,067965$ & $-0,118150$ & 0,013254 & 0,090427 \\
\hline Total & $-0,205790$ & 0,112160 & $-0,214760$ & $-0,064660$ \\
\hline Efeito direto de MC & $-0,148650$ & 0,172645 & 0,048683 & $-0,317324$ \\
\hline via FL & $-0,10890$ & 0,048438 & $-0,112733$ & 0,000920 \\
\hline Efeito direto de EP & $-0,274133$ & 0,221129 & 0,163272 & $-0,155001$ \\
\hline via FL & $-0,004966$ & 0,022069 & $-0,051362$ & 0,000419 \\
\hline via $\mathrm{MC}$ & $-0,039510$ & 0,045887 & 0,012940 & $-0,084341$ \\
\hline via PIL & $-0,038102$ & $-0,066235$ & 0,007430 & 0,050693 \\
\hline Total & $-0,356710$ & 0,222850 & 0,132280 & $-0,188230$ \\
\hline Efeito direto de PIL & $-0,235093$ & $-0,408683$ & 0,045847 & 0,312786 \\
\hline via FL & $-0,007768$ & 0,034524 & $-0,080351$ & 0,000655 \\
\hline via $\mathrm{MC}$ & $-0,014795$ & 0,017183 & 0,004845 & $-0,31583$ \\
\hline via EP & $-0,044053$ & 0,035535 & 0,026238 & $-0,024909$ \\
\hline Total & $-0,301710$ & $-0,321440$ & $-0,003420$ & 0,256950 \\
\hline
\end{tabular}

${ }^{1 /} \mathrm{FL}=$ número de dias para a floração; $\mathrm{MC}=$ número de dias para a maturação de colheita; $\mathrm{EP}=$ estatura de planta em $\mathrm{cm} ; \mathrm{PIL}=$ ponto de inserção do primeiro legume; NGL= número de grãos por legume; NLP= número de legumes por planta; $\mathrm{PMG=}$ peso de mil grãos; $\mathrm{POP}=$ número de plantas por unidade de área. 
determinante das variações na variável principal, e, conseqüentemente, prediz que a seleção indireta não será eficaz, comparativamente com a seleção direta. Assim, para o caráter NGL, nenhuma variável secundária está associada a este caráter variável. A variável NGL não tem importância relevante na obtenção de resposta correlacionada com caracteres secundários.

O componente primário PMG teve como principal determinante a variável $\mathrm{EP}$, com relação ao efeito direto relativamente baixo e concordante em sinal e magnitude. Para aumentar o peso de mil grãos, deve-se, portanto, considerar os fatores causais estatura de planta, estatura de inserção do primeiro legume e número de dias até a maturação de colheita.

Os componentes secundários FL, MC e EP apresentaram efeito direto e correlação positiva para o NLP. Nem sempre os resultados das correlações foram concordantes em magnitude e sinais quando comparados com os efeitos diretos para todos os componentes primários. Nesses casos, os fatores causais indiretos devem ser considerados simultaneamente na seleção. Por exemplo, o caráter PMG evidenciou um coeficiente de correlação negativo e de pequena relevância $(-0,02)$ quando relacionado com o caráter $\mathrm{MC}$, porém, este fato não foi observado para o efeito direto de $\mathrm{MC}$ sobre o PMG que foi aproximadamente 4,0 vezes superior à estimativa do coeficiente de determinação total.

Devido aos baixos coeficientes de determinação e aos altos valores residuais em todas as análises de trilha dos componentes secundários sobre os primários, essas observações devem ser cuidadosamente avaliadas em ensaios posteriores. Contudo, os resultados obtidos para os componentes primários e secundários são concordantes com os apresentados por SANTOS et al. (1994) e SHORAN (1982)

\section{CONCLUSÕES}

A análise dos coeficientes de trilha apontou que os componentes primários, número de legumes por planta e peso de mil grãos, têm o maior efeito direto sobre o rendimento de grãos. Plantas de maturação precoce e de estatura elevada incrementaram o número de legumes por planta, enquanto a estatura de plantas influencia o peso de mil grãos.

\section{REFERÊNCIAS BIBLIOGRÁFICAS}

BALDISSERA, I.T., SCHERER, E.E. Correção da acidez do solo e adubação da cultura do feijão. In: EPAGRI. A cultura do feijão em Santa Catarina. Florianópolis: EPAGRI, Cap. 6, p. 115-136, 1992
BISOGNIN, D.A, ALMEIDA, L.A., GUIDOLIN, A.F. et al. Desempenho de cultivares de feijão em semeadura tardia no Planalto Catarinense. Ciência Rural, Santa Maria, v. 27, n. 2. p. 193-199, 1997.

CENTRO INTERNACIONAL DE AGRICULTURA TROPICAL. Sistema estándar para la evaluación de germoplasma de frijol. 2. ed. Colômbia: Cali, 1991. 56 p.

COLLICCHIO, E., RAMALHO, M.A.P., ABREU, A.F Associação entre porte da planta do feijoeiro e o tamanho de grãos. Pesquisa Agropecuária Brasileira, Brasília, v. 32, n. 3, p. 297-304, 1997.

CRUZ, C.D., REGAZZI, A.J. Modelos biométricos aplicados ao melhoramento genético. 2. ed. Viçosa: UFV, 1997. 390 p.

CRUZ, C.D. Aplicativo computacional em genética e estatística. Viçosa: UFV, Imprensa Universitária, 442 p., 1997.

FALCONER, D.S. Introdução à genética quantitativa. Viçosa: UFG, Imprensa Universitária, 1987. 279 p

FEHR, W.R. Principles of cultivars development. New York: Macmillan Publishing Company, 1987. V. I., 536 p.

MIRANDA, J.E.C., CRUZ, C.D., PEREIRA. A.S. Análise de trilha e divergência genética de cultivares e clones de Batatadoce. Revista Brasileira de Genética, Ribeirão Preto, v. 11, n. 4, p. 881-904, 1988.

NADAL, R. Aspectos econômicos da cultura do feijão. In EPAGRI. A cultura do feijão em Santa Catarina. Florianópolis: EPAGRI, 1992. Cap. 1, p. 25-34.

RAMALHO, M.A.P., SANTOS, J.B., ZIMMERMANN, M,J de $O$. Genética quantitativa em plantas autógamas. Aplicações ao Melhoramento do Feijoeiro. Goiânia: UFG, 1993. $271 \mathrm{p}$

RAMALHO, M.A.P., VENCOVSKY, R. Estimação dos componentes da variância genética em plantas autógamas. Ciência e Prática, Lavras, v. 10, n. 2, p. 117-140, 1978.

RAMALHO, M.A.P., SANTOS, J.B., SANTA CECÍLIA, F.C. et al. Seleção de progênies no feijão "Pintado" e estimativa dos parâmetros genéticos e fenótipicos. Ciência e Prática, Lavras, v. 3, p. $51-57,1979$.

SANTOS, C.A.F., CAVALCANTI, J., PAINI, J.N, $\boldsymbol{e} \boldsymbol{a} \boldsymbol{a}$. Correlações canônicas entre componentes primários e secundários na produção de grãos em Guandu (Cajanus cajan (L.) Millsp). Revista Ceres, Viçosa, v. 41, n. 236, p. 456-464, 1994

SANTOS, C.A.F., MENEZES, E.A., PAINI, J.N. $\boldsymbol{e} t \boldsymbol{a l}$. Coeficiente de trilha no estudo dos componentes primários e secundários na produção de grãos do Guandu (Cajanus cajan (L.) Millsp). Revista Ceres, Viçosa, v. 41, n. 235, p. 299-305, 1994

SANTOS, J., VENCOVSKY, R. Correlação fenotípica e genética entre alguns caracteres agronômicos do feijoeiro (Phaseolus vulgaris L.). Ciência e Prática, Lavras, v. 10, n. 3, p. 265272, 1986.

SHORAN, J. Path analysis in pigeonpea. Indian Journal of Genetics. New Delhi, v. 42, p. 319-321, 1982.

WILDNER, L.P. Manejo do solo para cultura do feijão: Principais características e recomendações técnicas. In: EPAGRI. A cultura do feijão em Santa Catarina. Florianópolis: EPAGRI, 1992, Cap. 5, p. 83-114. 